\title{
Squamous bronchial carcinoma arising in a case of multiple juvenile papillomatosis
}

\author{
NS DALLIMORE \\ From the Department of Pathology, University of Wales College of Medicine, Cardiff
}

Juvenile papillomatosis of the larynx and trachea is a rare but well recognised condition, classically developing between the ages of 5 and 15 years but occasionally occurring in infancy. The tumours tend to recur before puberty but rarely do so afterwards. Malignant transformation is said not to complicate this condition.' This report describes a case of squamous carcinoma arising in a patient with laryngeal papillomatosis, without previous radiotherapy.

\section{Case report}

The patient first presented to a hospital in Germany at the age of 3 years with laryngeal obstruction due to multiple laryngeal papillomas, which were resected. There was no family history of papillomas and she was otherwise normal. Over the next two years she had eight further resections of laryngeal papillomas and a temporary tracheostomy. At the age of 5 years she was admitted to Llandough Hospital with an upper respiratory tract infection.

Indirectly laryngoscopy on admission showed the glottis partially obstructed by multiple papillomas of the vocal cords and the base of the epiglottis. These were removed during direct laryngoscopy. A tracheostomy was reestablished. Histological examination of resected material showed benign squamous papillomas with no evidence of dysplasia.

Over the next three years she had 16 laryngoscopies for removal of benign polyps from the larynx, trachea, and carina. At the age of 8 oestradiol vallenate and methyl testosterone were given in an attempt to induce puberty. This did not affect the rate of recurrence of the polyps and treatment was discontinued. For the next nine years the papillomas continued to recur. Two to three resections a year were performed. The histological appearances of the resected papillomas were of benign papillomas covered by mixtures of respiratory, squamous, and transitional epithelium with no evidence of dysplasia. At the age of 17 years she developed dysphagia. A barium meal showed a tumour compressing the lower oesophagus and eroding the 10 th and 11 th ribs. Biopsy of the rib lesion showed a well differentiated squamous carcinoma. Despite an initial response to radiotherapy she died six months later.

At necropsy the body was that of an emaciated young women. There was a tracheostomy present. There was a 6 $\times 4 \mathrm{~cm}$ ulcer on the dorsal surface of the trunk at the level of L1-4 with necrotic tumour in the base. The larynx, trachea, and main bronchi contained about 20 friable papillomas, up to $1 \mathrm{~cm}$ in diameter. There was a firm, Address for reprint requests: Dr NS Dallimore, Department of Pathology, University of Wales College of Medicine, Cardiff CF4 4XW.

Accepted 1 March 1985 greyish tumour in the lower lobe bronchus, invading the surrounding parenchyma and replacing the whole of the lower lobe. The hilar nodes were also replaced by tumour. There were extensive tumour deposits in both paravertebral gutters with invasion of the aorta, vena cava, oesophagus, spinal canal, spleen, and pancreas. Histological examination showed the papillonias to be benign and covered by a mixture of squamous, transitional, and respiratory mucosa (fig 1 ). There was no evidence of dysplasia or increased mitotic activity. None showed invasion of the base.

Sections of the main tumour and of the secondary deposits showed a well differentiated squamous carcinoma (fig 2).

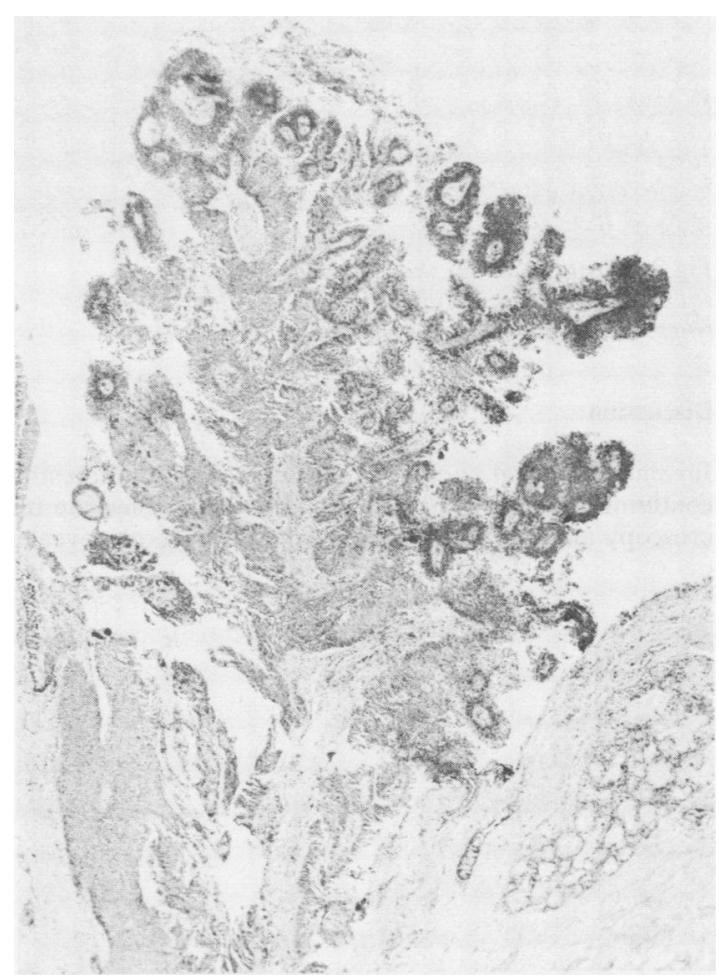

Fig 1 Benign papilloma of the trachea, covered by a mixture of transitional and respiratory type epithelium. (Haematoxylin and eosin, $\times 30$.) 


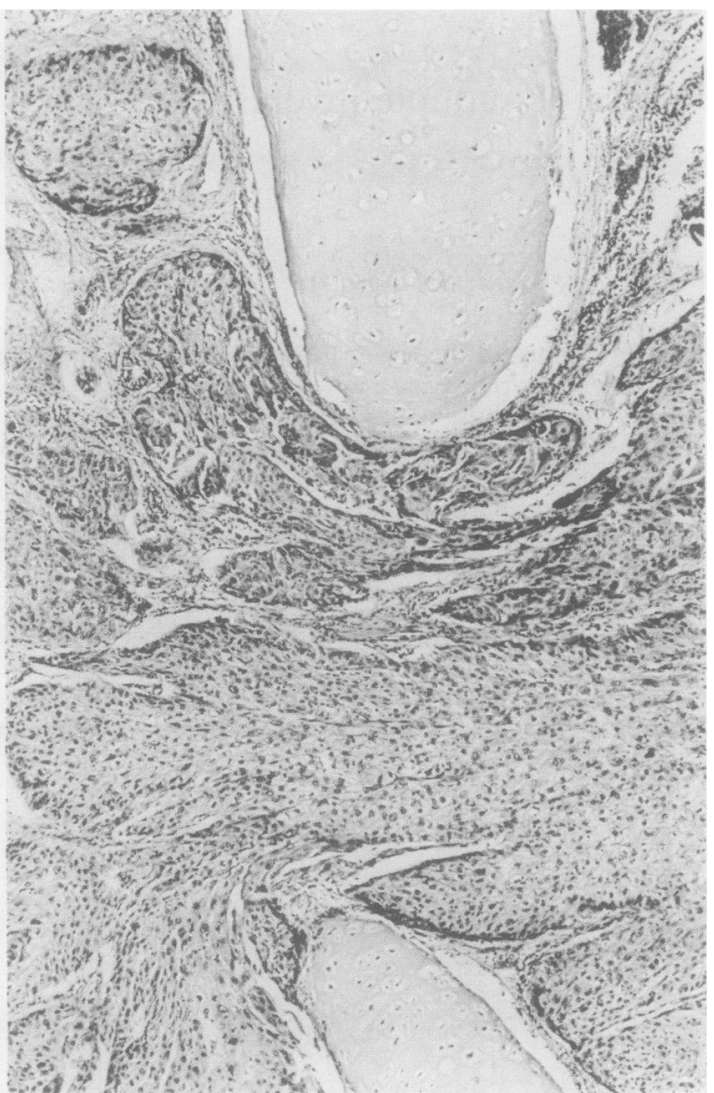

Fig 2 Bronchial wall showing well differentiated squamous carcinoma invading between the cartilage rings. (Haematoxylin and eosin, $\times 100$.)

\section{Discussion}

Juvenile laryngeal papillomatosis is a rare and interesting condition thought to have a viral aetiology. Electron microscopy and the use of DNA probes have both revealed human papilloma virus in the papillomas in some cases. ${ }^{23}$ It has been assumed that the tumours are caused by the virus, as is known to occur in animals. The virus has antigenic similarity to a genital papilloma virus. It has been suggested that juvenile laryngeal papillomatosis may result from perinatal infection from the mother. ${ }^{2}$

Although death may occur from laryngeal or tracheal obstruction ${ }^{4}$ juvenile laryngeal papillomatosis is usually a self limiting disease..$^{5}$ In contrast, papillomatosis in adults has a very high risk of subsequent malignancy. ${ }^{6}$ In previously reported cases carcinoma complicating juvenile laryngeal papillomatosis has followed 6-20 years after radiotherapy. ${ }^{18}$ There has been only one previously reported case in which no history of radiotherapy was given. ${ }^{9}$ The patient had papillomas from the age of 6 years. Lobectomy at the age of $\mathbf{2 8}$ for a mass evident on the chest radiograph showed a papilloma with invasion of the base by squamous carcinoma but no more distant spread.

In the present case, although there is no proof of the cause of the carcinoma, it can be suggested that malignancy arose as a consequence of long standing viral infection.

\section{References}

1 Majoros M, Devine KD, Parkhill EM. Malignant transformation of benign layngeal papillomas in children after radiation therapy. Surg Clin N Am 1963;43:1049-61.

2 Quick CA, Faras A, Krzysek R. The aetiology of laryngeal papillomatosis. Laryngoscope 1978;88:1789-95.

3 Gissmann L, Diehl V, Shultz-Coulon H, Hausen H. Molecular cloning and characterization of human papilloma virus DNA derived from a laryngeal papilloma. $J$ Virol 1982;44:393-400.

4 Hitz HB, Oesterlin E. A case of multiple papillomata of the larynx with aerial metastases to lungs. Am J Pathol 1982;8:333-9.

5 Capps FCW. Benign tumours of the larynx. $J$ Laryngol Otol 1957;71:709-17.

6 Al-Saleem T, Peale AR, Norris CM. Multiple papillomatosis of the lower respiratory tract. Cancer $1968 ; 22: 1173-84$.

7 Buffmire DK, Clagett OT, McDonald JR. Papillomas of the larynx, trachea and bronchi. Proc Mayo Clin 1960;25:595600.

8 Fechner RE, Goepfert H, Alford BR. Invasive laryngeal papillomatosis. Arch Otolaryngol 1974;99:147-51.

9 Spencer H, Dail DH, Arneaud J. Non-invasive bronchial epithelial papillary tumours. Cancer 1980;45:1486-97. 